
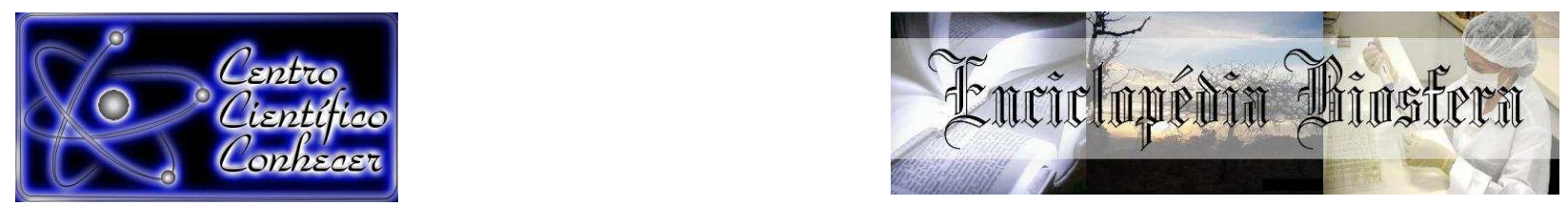

\title{
CONHECIMENTO E USO TRADICIONAL DAS ESPÉCIES MADEIREIRAS E MEDICINAIS UTILIZADAS NO MUNICÍPIO DE ALDEIAS ALTAS, MARANHÃO, BRASIL
}

Miguel Sena de Oliveira $^{1}$, Eduardo Oliveira Silva ${ }^{2}$, Alessandro Wagner Coelho Ferreira ${ }^{3}$ Elidio Armando Exposto Guarçoni ${ }^{4}$

1 Curso de Ciências Biológicas, Universidade Estadual do Maranhão, CESC/UEMA

Caxias, Maranhão, Brasil. E-mail: miguelsena2010@hotmail.com

2 Prof. Assistente da Universidade Federal do Maranhão, UFMA/Codó, Maranhão, Brasil

3 Prof. Assistente da Universidade Federal do Maranhão, UFMA/São Luís, Maranhão, Brasil

4 Prof. Assistente da Universidade Federal do Maranhão, UFMA/Bacabal, Maranhão, Brasil

Recebido em: 03/10/2016 - Aprovado em: 21/11/2016 - Publicado em: 05/12/2016 DOI: 10.18677/EnciBio_2016B_109

\begin{abstract}
O objetivo desse estudo foi realizar um inventario etnobotânico das espécies madeireiras e medicinais utilizadas no município de Aldeias Altas - MA. Para isso, foram realizadas aplicação de questionários semiestruturados, além de conversas informais com proprietários de serrarias e raizeiros. Foram listadas 49 espécies de uso popular no município, das quais seis espécies (12\%) foram citadas somente para o uso madeireiro; 38 espécies $(78 \%)$ somente para o uso medicinal e cinco espécies (10\%) em ambas as categorias de uso. As famílias mais representativas foram, Fabaceae e Lamiaceae, com espécies madeireiras e medicinais usadas de modo frequente pela população como fonte de renda, energia e saúde. Nesse sentido, faz-se necessários mais estudos que ampliem esses conhecimentos sobre essas espécies, e suas utilizações de maneira mais segura e sustentável.
\end{abstract}

RESUMO

PALAVRAS-CHAVE: Cerrado, espécies madeireiras, plantas medicinais

\section{TRADITIONAL KNOWLEDGE AND USE OF TIMBER SPECIES AND MEDICINAL USED IN THE MUNICIPALITY ALDEIAS ALTAS, MARANHÃO, BRASIL}

\begin{abstract}
This paper aimed to inventory the plants ethnobotanical survey of medicinal plants, timber used in the municipality of Aldeias Altas-MA. The data were obtained through semi-structured interviews, beyond conversations with informants (owners of sawmills and herbalists). The results showed the occurrence of 49 plant species, on what six 78 species $(12 \%)$ only used as timber, 38 species $(78 \%)$ medicinal plants, and five species $(10 \%)$ in both modes. This study listed 49 species, of which six species $(12 \%)$ are used only as timber, $38 \mathrm{spp} .(78 \%)$ only as medicinal plants and five $(10 \%)$ in both categories. The most representative families were Fabaceae and Lamiaceae, with timber species and medicinal plants, frequently used as a source of
\end{abstract}


income energy and health. In this sense, there is a need for more studies to increase knowledge of these species, and their uses in an efficient and sustainable way

KEYWORDS: Thick, wood species, medicinal plants

\section{INTRODUÇÃO}

As plantas têm sido utilizadas pelo homem para diversas finalidades desde os primórdios da história da civilização. Com o passar dos séculos, esses conhecimentos foram acumulados e repassados por gerações, até os dias atuais. Em muitas comunidades, esse conhecimento fica retido às pessoas mais velhas, pois são esses que tendem a conhecer mais sobre assuntos de interesse para a comunidade, e são respeitados pelo seu saber (BATTISTI et al., 2013). Dessa forma, os conhecimentos etnobotânicos contribuem diretamente na preservação dos saberes tradicionais, e na utilização dos vegetais em benefício do próprio homem.

Os estudos etnobotânicos são necessários, pois os saberes tradicionais que as populações detêm, quando submetidos a testes científicos, podem ser utilizadas pela sociedade, podendo gerar produtos mais acessível em relação ao custo/benefício, contribuindo assim para uma melhor qualidade de vida da população (MARTINS et al., 2005). No Maranhão, ainda são poucos os trabalhos etnobotânicos que enfatizam aspectos sobre os potenciais madeireiros e medicinais das espécies vegetais utilizadas no estado, tanto em áreas urbanas quanto quilombolas, entre os quais podem ser citados os de SILVA et al. (2009), OLIVEIRA JUNIOR \& CONCEIÇÃO (2010), NASCIMENTO \& CONCEIÇÃO (2011), ARAUJO et al. (2015) e OLIVEIRA et al. (2016). O objetivo dessa pesquisa foi realizar um levantamento da Flora madeireira e medicinal utilizadas na cidade de Aldeias Altas Maranhão, e descrever as utilidades e aplicações dessas espécies no cotidiano da população nesse município.

\section{MATERIAL E MÉTODOS}

\section{Área de estudo}

Elevada ao nível de cidade em 1961, Aldeias Altas (Figura 1), Localiza-se no estado do Maranhão, situada na Mesorregião do Leste Maranhense entre as coordenadas de 451'32" S e 4321'2" O, limitando-se com os municípios de Caxias a $31,1 \mathrm{~km}$ e Codó a 49,6 km, possui uma área territorial de 1.942,114 Km², e uma população estimada em 25.509 habitantes. Apresenta características de Cerrado como vegetação dominante e clima seco e subúmido (MARANHÃO, 2011; IBGE, 2016).

\section{Coleta de dados}

Para a obtenção das informações sobre plantas de usos madeireiro e medicinal, foram realizadas visitas mensais em Aldeias Altas (MA), entre os meses de agosto de 2015 a fevereiro de 2016, para aplicações de questionários específicos e conversas informais com os proprietários de serrarias e "raizeiros" (conhecedores do uso de plantas medicinais). Contudo, era previamente esclarecido o objetivo da pesquisa ao entrevistado, além da permissão antecipada para que fossem anotadas as informações fornecidas.

Os participantes foram amostrados pela aplicação da técnica de amostragem Snow ball "bola de neve" (BALDIN \& MUNHOZ, 2011), que consiste em várias entrevistas que iniciam com um informante de referência, e seguem uma sequência de indicações, até que estas comecem a se repetir. Assim, foram 
visitadas as serrarias e aos domicílios dos raizeiros (pessoas indicadas como detentoras do conhecimento, cultivo e uso tradicional de plantas medicinais).

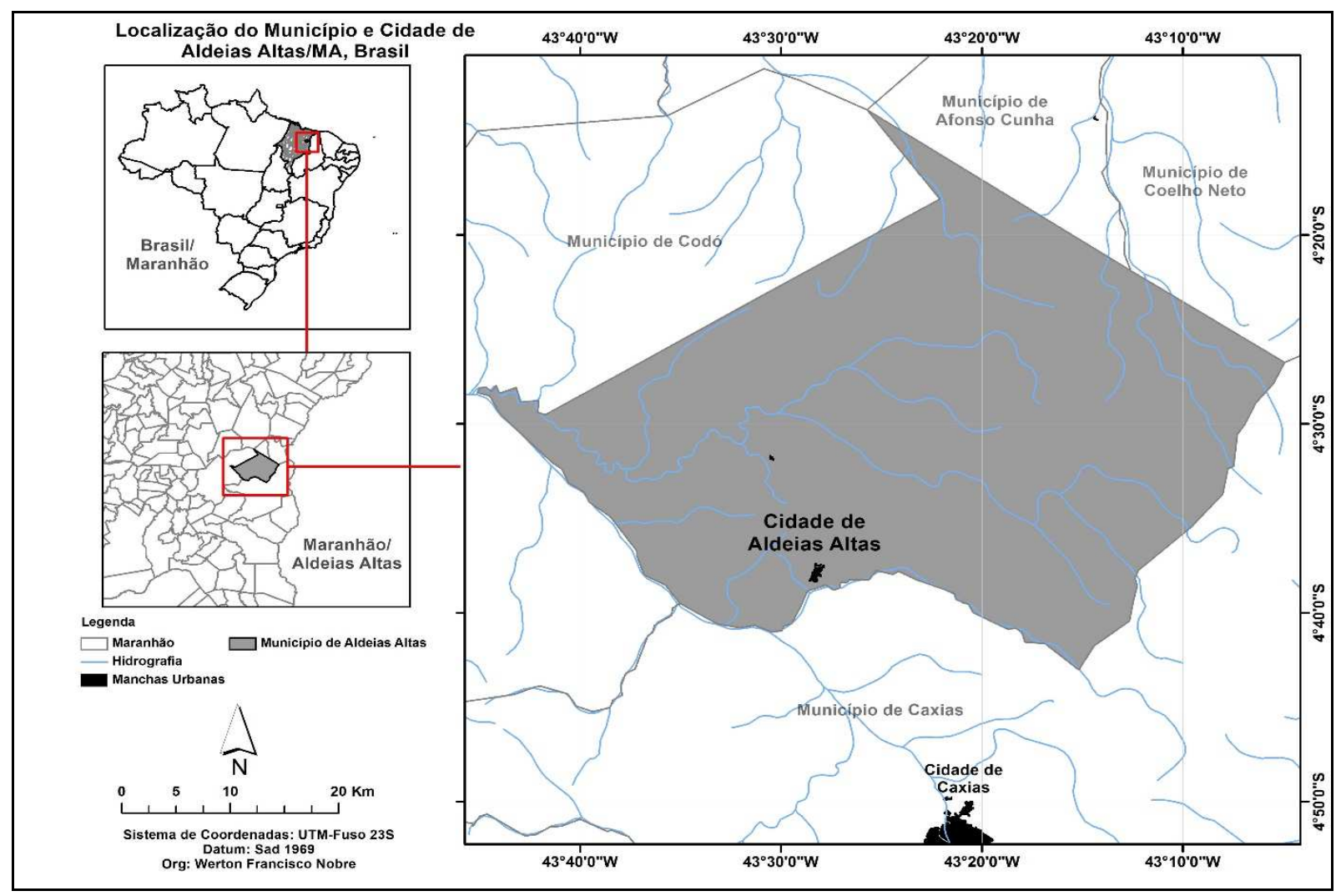

FIGURA 1: Localização da cidade de Aldeias Altas - MA. Fonte: ArcGis 9.3; Google Earth 2016; Organização SILVA, (2016)

As plantas medicinais foram agrupadas por categorias de uso medicinal, seguindo o modelo adaptado utilizado por ALBERTASSE et al. (2010). As espécies foram primeiramente reconhecidas nos locais, sempre pelo nome popular quando possível, sendo posteriormente identificadas por comparação com auxílio de literatura especializadas (ARAÚJO \& SILVA, 2000; ARAÚJO, 2002;SILVA et al., 2009; NASCIMENTO \& CONCEIÇÃO, 2011; OLIVEIRA et al., 2016) que tratam dos potencias madeireiros e medicinais de plantas nativas. As espécies foram classificadas de acordo com Sistema APGIII (2009), e para a escrita correta dos nomes científicos das espécies, foram consultadas as bases de dados atualizadas da Lista da FLORA DO BRASIL (2016).

\section{RESULTADOS E DISCUSSÃO}

Foram inventariadas 49 espécies, distribuídas em 25 famílias botânicas. As famílias Fabaceae com oito espécies (16\%), e Lamiaceae com seis espécies (12\%) foram as mais representativas com maior número de espécies. No potencial madeireiro, foram listadas 11 espécies utilizadas em sete serrarias na cidade. Essas espécies distribuíram-se em 8 famílias botânicas, sendo Fabaceae, Bignoniaceae e Moraceae as famílias mais representativas quanto ao número de espécie (QUADRO 1). Essas mesmas famílias estão entre as mais ocorrentes no trabalho de SILVA et 
al. (2009) no Cerrado Maranhense e ARAÚJO \& SILVA (2000) em fragmentos de floresta Amazônica no estado do Acre.

QUADRO 1. Espécies madeireiras utilizadas na cidade de Aldeias Altas - MA.

\begin{tabular}{|c|c|c|}
\hline FAMÍLIA & ESPÉCIE & NOME POPULAR \\
\hline Anacardiaceae & Astronium fraxinifolium Shortt. & Gonçalo Alves \\
\hline Apocynaceae & Himatanthus drasticus (Mart.) Plumel & Janaúba \\
\hline Bignoniaceae & $\begin{array}{c}\text { Handroanthus impetiginosus (Mart. ex } \\
\text { DC.) Mattos }\end{array}$ & Pau d'arco Roxo \\
\hline Bignoniaceae & $\begin{array}{c}\text { Handroanthus serratifolius (Vahl) } \\
\text { S.Grosev }\end{array}$ & Pau d'arco Amarelo \\
\hline Fabaceae & $\begin{array}{c}\text { Hymenaea stigonocarpa Mart. ex } \\
\text { Hayne }\end{array}$ & Jatobá \\
\hline Fabaceae & Pterodon emarginatus Vogel. & Sucupira Amarela \\
\hline Fabaceae & Plathymenia reticulata Benth & Candeia \\
\hline Malvaceae & Luehea divaricata Mart. \& Zucc. & Açoita Cavalo \\
\hline Meliaceae & Cedrela odorata L. & Cedro \\
\hline Moraceae & Brosimum gaudichaudii Trécul & Mama - cachorra \\
\hline Moraceae & Bagassa guianensis Aubl. & Amarelão \\
\hline
\end{tabular}

Dessas espécies madeireiras (Quadro 1), duas foram mencionadas por Alves et al. (2014) no estado do Pará; sete espécies foram encontradas por SILVA et al. (2009) no município de Caxias-MA, e outras nove por CALVI \& FERRAZ (2014) em um levantamento de espécies florestais de interesse econômico na Amazônia Ocidental. As espécies Pterodon emarginatus Vogel (sucupira amarela); Handroanthus impetiginosus (Mart. ex DC.) Mattos (Pau d'arco roxo) e Handroanthus serratifolius (Vahl) S.Grosev (Pau d'arco amarelo) são as mais utilizadas pelas serrarias. As demais espécies são usadas somente na ausência das principais.

Os proprietários dessas serrarias afirmaram que mesmo diante da baixa variedade de espécies utilizadas, o suprimento de madeira é suficiente para a demanda. Pelo observado, as espécies nativas são as mais utilizadas nas serrarias do município de Aldeias Altas (MA). Para SILVA \& ANDRADE (2005) e LIMA et al. (2011) os maiores índices de uso estão concentrados em espécies nativas, por serem as mais utilizadas e frequentemente encontradas nos fragmentos de florestas em áreas adjacentes as comunidades. Ao serem extraídas, as madeiras chegam na 
cidade em caminhões, e levadas as serrarias ainda em forma de toras roliças, sendo posteriormente vendidas em metros cúbicos aos proprietários das mesmas, assim a madeira bruta é trabalhada e transformada em produtos destinadas a construção civil ou domicílios.

Com relação aos produtos fabricados nas serrarias, a maior parte da produção tem seus destinos finais nas residências, onde os principais objetos são: mesas, cadeiras, camas, guarda roupas, armário entre outros que podem ser encomendados nas serrarias. A menor parte da produção é destinada para a construção civil, produção essa que se expressa em maior enfoque em portas e janelas, sendo esses os mais procurados. Uma outra aplicação da madeira é como combustível, pela queima do carvão e serragem, produzidos com as sobras da madeira e posteriormente comercializados. $\mathrm{O}$ uso do carvão pela população tornarse uma alternativa ao gás de cozinha nos domicílios. Já a serragem é empregada no aquecimento de caldeiras para a fabricação de tijolos.

A utilização de sobras de madeira como combustível representa o aproveitamento máximo da madeira extraída que chega as serrarias. Essa utilização, também é relatado no estado do Pará (GOMES \& SAMPAIO, 2004); Pernambuco (SILVA \& ANDRADE, 2005); Bahia (CERQUEIRA, 2012); Rio de Janeiro (BALDINI \& SILVA, 2007); e Maranhão (SILVA et al., 2009; OLIVEIRA et al., 2016). Porém, tornam-se necessários estudos que aprimorem o uso sustentável dos recursos madeireiros, além de uma gestão mais adequada dos seus resíduos de forma que promova um crescimento econômico em médio e longo prazo.

Para a categoria de plantas medicinais, foram visitados oito "raizeiros", dos quais apenas quatro se dispuseram a participar do estudo. Foram listadas 43 espécies de plantas medicinais (Quadro 2) distribuídas em 24 famílias botânicas, estando 38 identificadas ao nível de espécie e cinco não tiveram identificação taxonômica confirmada. Entre as espécies medicinais, cinco tem utilização madeireira nas serrarias de cidade $H$. drasticus (Janaúba); $H$. impetiginosus (Ipêroxo); P. reticulata (Candeia); H. stigonocarpa (Jatobá); P. emarginatus (Sucupira Amarela). As famílias Fabaceae, Lamiaceae foram as mais representativas em número de espécies, com oito e sete espécies cada uma. Em geral, essas famílias aparecem com maior número de espécies medicinais em vários levantamentos (SANTOS \& SILVA, 2015; FARIAS et al., 2015; ARAÚJO et al., 2015; e ALMEIDA NETO et al., 2015).

Para RIBEIRO et al., (2014), a predominância de espécies de uma mesma família botânica em determinada região, aumenta a probabilidade dessas espécies serem utilizadas de forma medicinal. De acordo com os entrevistados, $53 \%$ das espécies medicinais são coletas diretamente da natureza. As demais espécies, 47\% cultivas em seus próprios quintais pelos entrevistados. Diferentemente de FREITAS et al., (2012) e SOARES et al., (2009) que apontaram a prática do cultivo como principal forma de obtenção das espécies medicinais em seus trabalhos na Região Nordeste do Brasil.

Para o preparo dos fitoterápicos, as folhas (32\%) e cascas (19\%) (Quadro 2) foram os mais citadas. Outros trabalhos para o Nordeste do Brasil apontaram folhas e cascas como os mais utilizados (SOARES et al., 2009; NASCIMENTO \& CONCEIÇÃO, 2011; ALMEIDA NETO et al., 2015: OLIVEIRA et al., 2016).A preferência pelas folhas se dá pela facilidade de coletá-las e a disponibilidade destas durante todo o ano (CASTELLUCCI et al., 2000; VIEIRA et al., 2015).

Em relação à forma de preparo, a maior ênfase foi para o uso do chá $(44,1 \%)$, seguido pelos compostos prontos, as chamadas "garrafadas", com (37,5\%); de igual 
modo, relatados em outros trabalhos etnobotânicos (FRANCO \& BARROS, 2006; SILVA et al., 2012; LEITE et al., 2013; SILVA \& FARIA, 2014; SILVA et al., 2015). Em geral, as garrafadas são elaboradas da mistura de partes do vegetal (raízes, cascas, folhas) com bebidas alcoólicas (DANTAS et al., 2008), ou água, como mencionado pelos raizeiros da cidade de Aldeias Altas - MA.

As "garrafadas" são produzidas pelos "raizeiros" que geralmente são pessoas mais velhas e experientes no preparo das mesmas na localidade. Em geral as garrafadas são comercializadas em garrafas pet's de dois litros, a preços estabelecidos, dependendo da dificuldade para se obter os ingredientes (espécies) e o tempo para prepará-las. As doenças tratadas pelo uso dos fitoterápicos produzidos na cidade estão listadas abaixo (Figura 2), sendo que os usos mais frequentes foram para tratar febres, dores e inflamações, seguido por doenças relacionadas ao sistema digestório.

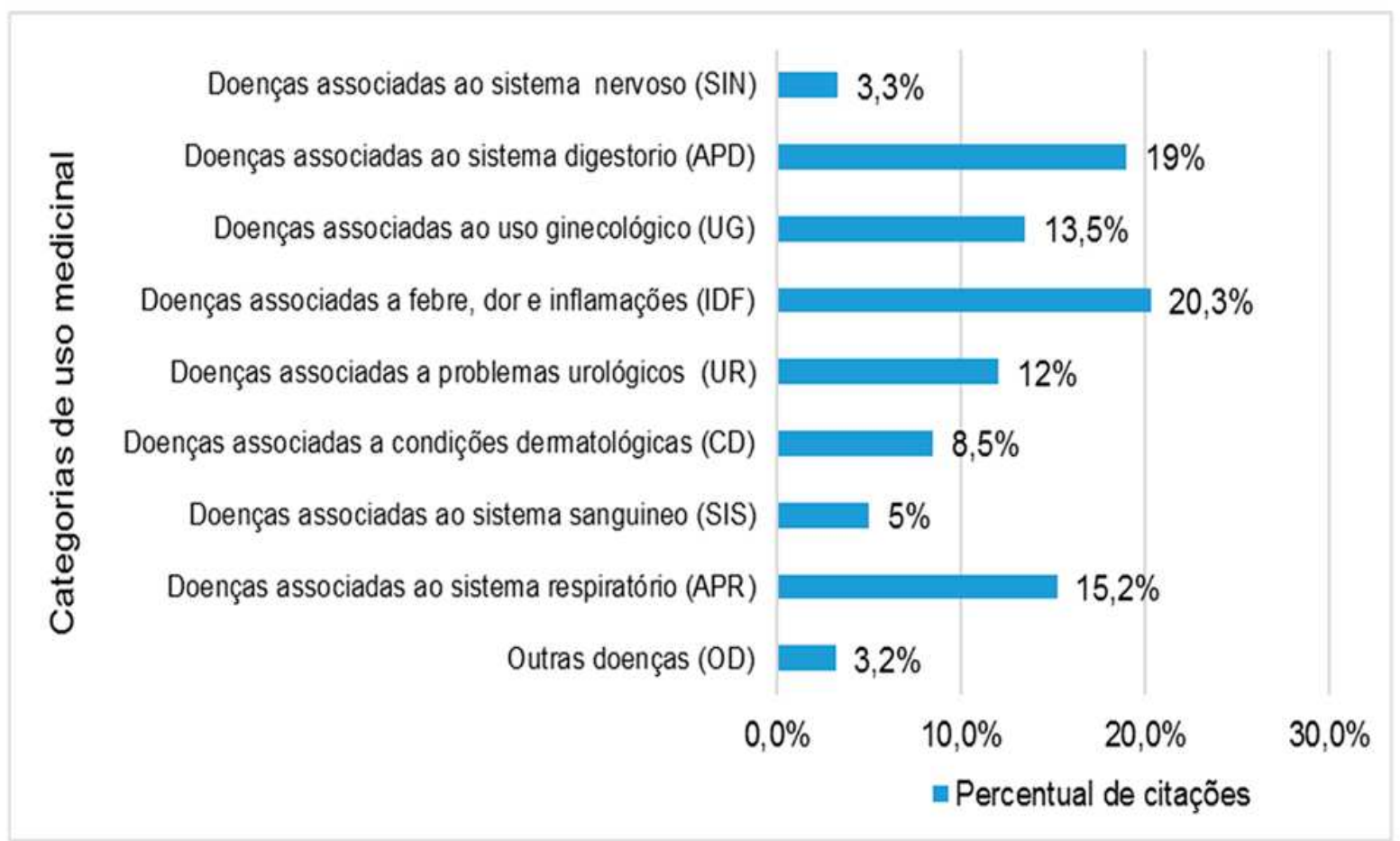

FIGURA 2: Percentual de citações pelo motivo do uso dos fitoterápicos.

QUADRO 2- Plantas citadas como medicinais na cidade de Aldeias Altas- MA.

\begin{tabular}{l|c|c|c|c|c|c}
\hline \hline $\begin{array}{c}\text { Família/ } \\
\text { Espécie/ } \\
\text { Nome Trivial }\end{array}$ & $\begin{array}{c}\text { Motivo do } \\
\text { uso }\end{array}$ & Preparo & $\begin{array}{c}\text { Parte } \\
\text { Usada }\end{array}$ & $\begin{array}{c}\text { Coleta ou } \\
\text { Cultivada }\end{array}$ & $\begin{array}{c}\text { Contra } \\
\text { Indicação }\end{array}$ & $\begin{array}{c}\text { Doses } \\
\text { Diárias }\end{array}$ \\
\hline $\begin{array}{l}\text { Amaranthace } \\
\text { ae } \\
\text { Dysphania }\end{array}$ & $\begin{array}{c}\text { Inflamaçõe } \\
\mathrm{s}\end{array}$ & Suco & $\begin{array}{c}\text { Planta } \\
\text { inteira }\end{array}$ & Cultivada & $\begin{array}{c}\text { Crianças } \\
\text { menores de } \\
\text { cinco anos }\end{array}$ & $\begin{array}{c}3 \text { ou 4x ao } \\
\text { dia }\end{array}$ \\
\hline $\begin{array}{l}\text { Anacardiacea } \\
\text { e } \\
\text { Anacardium }\end{array}$ & $\begin{array}{c}\text { Anti- } \\
\text { inflamatório } \\
\text { e }\end{array}$ & Chá & Cascas & Cultivada & $\begin{array}{c}\text { Mulheres } \\
\text { grávidas }\end{array}$ & 3x ao dia \\
\hline $\begin{array}{l}\text { Apocynaceae } \\
\text { Himatanthus } \\
\text { drasticus (Mart.) }\end{array}$ & $\begin{array}{c}\text { Regulação } \\
\text { menstrual }\end{array}$ & Garrafada & Cascas & Coletada & $\begin{array}{c}\text { Mulher } \\
\text { menstruada } \\
\text { garotas }\end{array}$ & $2 x$ ao dia \\
\hline
\end{tabular}




\begin{tabular}{|c|c|c|c|c|c|c|}
\hline $\begin{array}{l}\text { Bignoniaceae } \\
\text { Handroanthus } \\
\text { impetiginosus }\end{array}$ & Inflamação & $\begin{array}{l}\text { Garrafad } \\
\text { a }\end{array}$ & Entrecascas & Coletada & $\begin{array}{l}\text { Mulheres } \\
\text { grávidas }\end{array}$ & $3 x$ ao dia \\
\hline $\begin{array}{l}\text { Boraginaceae } \\
\text { Heliotropium } \\
\text { indicum L. }\end{array}$ & $\begin{array}{l}\text { Regulação } \\
\text { menstrual }\end{array}$ & Chá & Folhas & Coletada & $\begin{array}{c}\text { Mulheres } \\
\text { menstruada }\end{array}$ & $1 x$ ao dia \\
\hline $\begin{array}{l}\text { Cactaceae } \\
\text { Pereskia } \\
\text { grandifolia Ha }\end{array}$ & $\begin{array}{c}\text { Cicatrizant } \\
\mathrm{e}\end{array}$ & $\begin{array}{l}\text { Maceraç } \\
\text { ão }\end{array}$ & Folhas & Cultivada & Não tem & $2 x$ ao dia \\
\hline $\begin{array}{l}\text { Crassulaceae } \\
\text { Kalanchoe } \\
\text { pinnata (Lam.) }\end{array}$ & $\begin{array}{c}\text { Inflamaçõe } \\
\text { s e } \\
\text { cicatrizaçõ }\end{array}$ & Chá & Folhas & Cultivada & Não tem & $\begin{array}{l}2 x \text { ao dia } \\
\text { para } \\
\text { adultos e }\end{array}$ \\
\hline $\begin{array}{l}\text { Euphorbiacea } \\
\text { e } \\
\text { Ricinus }\end{array}$ & $\begin{array}{l}\text { Prisão de } \\
\text { ventre }\end{array}$ & Azeite & Sementes & Cultivada & Não tem & $1 x$ ao dia \\
\hline $\begin{array}{l}\text { Fabaceae } \\
\text { Libidibia ferrea } \\
\text { (Mart.) L.P. } \\
\text { Queiroz } \\
\text { (Jucá) }\end{array}$ & $\begin{array}{c}\text { Diarreias, } \\
\text { fígado e } \\
\text { cicatrizaçãa } \\
0\end{array}$ & Chá & Fruto & Coletada & $\begin{array}{c}\text { Crianças } \\
\text { menores } \\
\text { de cinco } \\
\text { anos }\end{array}$ & $2 x$ ao dia \\
\hline $\begin{array}{l}\text { Fabaceae } \\
\text { Anadenanther } \\
\text { a colubrina } \\
\text { var. cebil } \\
\text { (Griseb.) } \\
\text { Altschul } \\
\text { (Angico preto) }\end{array}$ & $\begin{array}{l}\text { Gripes, } \\
\text { gases }\end{array}$ & Chá & Casca & Coletada & $\begin{array}{l}\text { Mulheres } \\
\text { grávidas, } \\
\text { crianças } \\
\text { menores de } \\
\text { cinco anos }\end{array}$ & $2 x$ ao dia \\
\hline $\begin{array}{l}\text { Fabaceae } \\
\text { Senna } \\
\text { occidentalis } \\
\text { (L.) Link } \\
\text { (Fedegoso) }\end{array}$ & $\begin{array}{c}\text { Febre, } \\
\text { dores no } \\
\text { estômago } \\
\text { e gripes }\end{array}$ & Chá & Raiz & Coletado & $\begin{array}{c}\text { Mulheres } \\
\text { menstruada } \\
\mathrm{s} \text {, crianças } \\
\text { menores de } \\
\text { dois anos }\end{array}$ & $2 x$ ao dia \\
\hline $\begin{array}{l}\text { Fabaceae } \\
\text { Mimosa pigra } \\
\text { L. } \\
\text { (Calumbi) }\end{array}$ & $\begin{array}{c}\text { Anti- } \\
\text { inflamatório }\end{array}$ & Chá & Raízes & Coletada & $\begin{array}{l}\text { Mulheres } \\
\text { grávidas }\end{array}$ & $1 \mathrm{x}$ ao dia \\
\hline $\begin{array}{l}\text { Fabaceae } \\
\text { Plathymenia } \\
\text { reticulata Benth } \\
\text { (Candeia) }\end{array}$ & $\begin{array}{l}\text { Coração } \\
\text { grande }\end{array}$ & $\begin{array}{l}\text { Garrafad } \\
\text { a }\end{array}$ & Cascas & Coletada & $\begin{array}{c}\text { Crianças } \\
\text { menores de } \\
\text { quinze anos }\end{array}$ & $2 x$ ao dia \\
\hline $\begin{array}{l}\text { Fabaceae } \\
\text { Stryphnodendro } \\
\text { adstringens } \\
\text { (Mart.) Coville } \\
\text { (Baba-timão ) }\end{array}$ & $\begin{array}{c}\text { Próstata e } \\
\text { inflamações }\end{array}$ & $\begin{array}{c}\text { Garrafad } \\
\text { a }\end{array}$ & Entrecascas & Coletada & $\begin{array}{c}\text { Não } \\
\text { informado }\end{array}$ & $2 x$ ao dia \\
\hline $\begin{array}{l}\text { Fabaceae } \\
\text { Hymenaea } \\
\text { stigonocarpa } \\
\text { Mart. ex Hayne } \\
\text { (Jatobá) }\end{array}$ & $\begin{array}{l}\text { Próstata e } \\
\text { inflamações }\end{array}$ & $\begin{array}{l}\text { Garrafad } \\
\text { a }\end{array}$ & Entrecascas & Coletada & $\begin{array}{c}\text { Não } \\
\text { informado }\end{array}$ & $3 x$ ao dia \\
\hline
\end{tabular}




\begin{tabular}{|c|c|c|c|c|c|c|}
\hline $\begin{array}{l}\text { Fabaceae } \\
\text { Pterodon } \\
\text { emarginatus } \\
\text { Vogel } \\
\text { (Sucupira } \\
\text { amarela) } \\
\end{array}$ & $\begin{array}{c}\text { Inflamaçõe } \\
\mathrm{s}\end{array}$ & $\begin{array}{c}\text { Garrafad } \\
\text { a }\end{array}$ & Cascas & Coletada & $\begin{array}{l}\text { Mulheres } \\
\text { grávidas }\end{array}$ & $3 x$ ao dia \\
\hline $\begin{array}{l}\text { Lamiaceae } \\
\text { Melissa officin } \\
\text { alis L. } \\
\text { (Erva cidreira) }\end{array}$ & Calmante & Chá & Folhas & Cultivada & $\begin{array}{l}\text { Pessoas } \\
\text { com } \\
\text { pressão } \\
\text { baixa }\end{array}$ & $2 x$ ao dia \\
\hline $\begin{array}{l}\text { Lamiaceae } \\
\text { Mentha sp. } \\
\text { (Hortelã) }\end{array}$ & $\begin{array}{c}\text { Dores de } \\
\text { barriga e } \\
\text { gripes }\end{array}$ & Chá & $\begin{array}{c}\text { Folhas e } \\
\text { caule }\end{array}$ & Cultivada & Não tem & $2 x$ ao dia \\
\hline $\begin{array}{l}\text { Lamiaceae } \\
\text { Plectranthus } \\
\text { amboinicus (L } \\
\text { our.) Spreng. }\end{array}$ & Gripes & $\begin{array}{c}\text { Lambed } \\
\text { or }\end{array}$ & $\begin{array}{c}\text { Folhas e } \\
\text { flores }\end{array}$ & Cultivada & Não tem & $1 \mathrm{x}$ ao dia \\
\hline $\begin{array}{l}\text { Lamiaceae } \\
\text { Plectranthus } \\
\text { ornatus Codd } \\
\text { (Boldo miúdo) }\end{array}$ & $\begin{array}{c}\text { Dores de } \\
\text { barriga }\end{array}$ & Chá & Folhas & Cultivada & $\begin{array}{c}\text { Mulheres } \\
\text { menstruada } \\
\mathrm{s} \text {, crianças } \\
\text { menores de } \\
\end{array}$ & $2 x$ ao dia \\
\hline $\begin{array}{l}\text { Lamiaceae } \\
\text { Plectranthus } \\
\text { barbatus Andr. } \\
\text { (Boldo da } \\
\text { terra) }\end{array}$ & Gastrite & $\begin{array}{l}\text { Garrafad } \\
\text { a }\end{array}$ & Planta toda & Cultivada & $\begin{array}{l}\text { Mulheres } \\
\text { grávidas }\end{array}$ & $3 x$ ao dia \\
\hline $\begin{array}{l}\text { Lamiaceae } \\
\text { Mentha } \\
\text { arvensis L. } \\
\text { (Viki) }\end{array}$ & Tosse & Chá & Folhas & Cultivada & Não tem & $4 x$ ao dia \\
\hline $\begin{array}{l}\text { Lamiaceae } \\
\text { Rosmarinus } \\
\text { officinalis L. } \\
\text { (Alecrim) }\end{array}$ & Sinusites & Chá & Folhas & Cultivadas & Não tem & $3 x$ ao dia \\
\hline $\begin{array}{l}\text { Lecythidaceae } \\
\text { Lecythis pisonis } \\
\text { Cambess. } \\
\text { (Sapucai) }\end{array}$ & Diabetes & $\begin{array}{l}\text { Garrafad } \\
\text { a }\end{array}$ & Cascas & Coletada & $\begin{array}{c}\text { Não } \\
\text { informado }\end{array}$ & $3 x$ ao dia \\
\hline $\begin{array}{l}\text { Myrtaceae } \\
\text { Eucalyptus } \\
\text { globulus Labill. } \\
\text { (Euclipto) }\end{array}$ & Gripes & Chá & Folhas & Coletada & Não tem & $2 x$ ao dia \\
\hline $\begin{array}{l}\text { Myrtaceae } \\
\text { Psidium } \\
\text { guajava L. } \\
\text { (Goiaba) }\end{array}$ & $\begin{array}{c}\text { Dores de } \\
\text { barriga }\end{array}$ & Chá & Folhas & Cultivada & $\begin{array}{l}\text { Crianças } \\
\text { menores de } \\
\text { três anos }\end{array}$ & $2 x$ ao dia \\
\hline
\end{tabular}




\begin{tabular}{|c|c|c|c|c|c|c|}
\hline $\begin{array}{l}\text { Meliaceae } \\
\text { Azadirachta } \\
\text { indica A.Juss. } \\
\text { (Nim) }\end{array}$ & Diabetes & Chá & Folhas & Cultivadas & $\begin{array}{c}\text { Não } \\
\text { informado }\end{array}$ & $3 x$ ao dia \\
\hline $\begin{array}{l}\text { Moraceae } \\
\text { Brosimum } \\
\text { gaudichaudii } \\
\text { Trécul } \\
\text { (Inharé) }\end{array}$ & $\begin{array}{c}\text { Regulação } \\
\text { menstrual e } \\
\text { dores nas } \\
\text { articulações }\end{array}$ & $\begin{array}{l}\text { Garrafad } \\
\text { a }\end{array}$ & Cascas & Coletada & $\begin{array}{l}\text { Mulheres } \\
\text { gravidas }\end{array}$ & $3 x$ ao dia \\
\hline $\begin{array}{l}\text { Nyctaginaceae } \\
\text { Boerhavia diffus } \\
\text { L. } \\
\text { (Pega-pinto) }\end{array}$ & $\begin{array}{l}\text { Problemas } \\
\text { renais }\end{array}$ & $\begin{array}{l}\text { Garrafad } \\
\text { a }\end{array}$ & Raiz & Coletada & Não tem & $3 x$ ao dia \\
\hline $\begin{array}{l}\text { Olacaceae } \\
\text { Ximenia } \\
\text { americana L. } \\
\text { (Ameixa) }\end{array}$ & $\begin{array}{r}\text { Inflamações } \\
\text { regulação } \\
\text { menstrual }\end{array}$ & $\begin{array}{l}\text { Garrafad } \\
\text { a }\end{array}$ & Entrecascas & Coletada & $\begin{array}{c}\text { Mulheres } \\
\text { menstruada } \\
\text { e mulheres } \\
\text { gravidas }\end{array}$ & $3 x$ ao dia \\
\hline $\begin{array}{l}\text { Orchidaceae } \\
\text { Catasetum sp. } \\
\text { (Banana - } \\
\text { brava) }\end{array}$ & $\begin{array}{c}\text { Cicatrizaçã } \\
0\end{array}$ & In-natura & $\begin{array}{l}\text { Pseudo- } \\
\text { bulbo }\end{array}$ & Coletada & $\begin{array}{l}\text { Crianças } \\
\text { menores de } \\
\text { cinco anos }\end{array}$ & $1 x$ ao dia \\
\hline $\begin{array}{l}\text { Plantaginace } \\
\text { ae } \\
\text { Scoparia } \\
\text { dulcis L. }\end{array}$ & $\begin{array}{l}\text { Dores na } \\
\text { bexiga e } \\
\text { rins }\end{array}$ & Chá & Raiz & Coletado & Não tem & $1 x$ ao dia \\
\hline $\begin{array}{l}\text { Phyllanthace } \\
\text { ae } \\
\text { Phyllanthus } \\
\text { niruri L. }\end{array}$ & $\begin{array}{l}\text { Problemas } \\
\text { renais }\end{array}$ & Chá & $\begin{array}{l}\text { Raiz e } \\
\text { folhas }\end{array}$ & Coletado & $\begin{array}{l}\text { Crianças } \\
\text { menores de } \\
\text { cinco anos }\end{array}$ & $2 x$ ao dia \\
\hline $\begin{array}{l}\text { Punicaceae } \\
\text { Punica } \\
\text { granatum L. }\end{array}$ & $\begin{array}{c}\text { Inflamaçõe } \\
\text { s na } \\
\text { garganta }\end{array}$ & In-natura & Fruto & Cultivada & Não tem & $\begin{array}{c}2 \text { ou } 3 x \text { ao } \\
\text { dia }\end{array}$ \\
\hline $\begin{array}{l}\text { Rubiaceae } \\
\text { Morinda } \\
\text { citrifolia L. } \\
\text { (Noni) }\end{array}$ & $\begin{array}{c}\text { Anti- } \\
\text { inflamatório } \\
, \\
\text { Regulação } \\
\text { intestinal e } \\
\text { menstrual }\end{array}$ & Suco & Fruto & Cultivada & $\begin{array}{c}\text { Mulher } \\
\text { menstruada } \\
\text {, quem tem } \\
\text { gastrite e } \\
\text { úlcera e } \\
\text { crianças } \\
\end{array}$ & $2 x$ ao dia \\
\hline $\begin{array}{l}\text { Simaroubace } \\
\text { ae } \\
\text { Simaba } \\
\text { maiana Casar. } \\
\text { (Pau pra tudo) }\end{array}$ & $\begin{array}{l}\text { Diabetes e } \\
\text { febres }\end{array}$ & Chá & $\begin{array}{l}\text { Raiz e } \\
\text { Cascas }\end{array}$ & Coletada & $\begin{array}{l}\text { Crianças } \\
\text { menores de } \\
\text { sete anos, } \\
\text { mulheres } \\
\text { menstruada }\end{array}$ & $1 \mathrm{x}$ ao dia \\
\hline $\begin{array}{l}\text { Zingiberacea } \\
\text { e } \\
\text { Zingiber }\end{array}$ & In-natura & In-natura & Caule & Cultivada & $\begin{array}{c}\text { Crianças } \\
\text { menores de } \\
\text { cinco anos }\end{array}$ & $2 x$ ao dia \\
\hline $\begin{array}{l}\text { Zingiberacea } \\
\text { e } \\
\text { Alpinia }\end{array}$ & Tonturas & Chá & Folhas & Cultivadas & Não tem & $3 x$ ao dia \\
\hline
\end{tabular}




\begin{tabular}{l|r|l|l|l|l|l}
\hline Caroba & $\begin{array}{c}\text { Inflamações } \\
\text { no útero }\end{array}$ & $\begin{array}{c}\text { Garrafad } \\
\text { a }\end{array}$ & Entrecascas & Coletada & $\begin{array}{r}\text { Não } \\
\text { informado }\end{array}$ & 3x ao dia \\
\hline $\begin{array}{l}\text { Mangaba de } \\
\text { Bode }\end{array}$ & $\begin{array}{c}\text { Inflamações } \\
\text { no } \\
\text { Útero }\end{array}$ & $\begin{array}{l}\text { Garrafad } \\
\text { a }\end{array}$ & Entrecascas & Coletada & $\begin{array}{c}\text { Não } \\
\text { informado }\end{array}$ & 3x ao dia \\
\hline Merasilina & Diarreia & $\begin{array}{l}\text { Garrafad } \\
\text { a }\end{array}$ & Folhas & Cultivada & $\begin{array}{r}\text { Mulheres } \\
\text { menstruada } \\
\text { e grávidas }\end{array}$ & 3x ao dia \\
\hline Pau chapada & $\begin{array}{c}\text { Regulação } \\
\text { menstrual }\end{array}$ & $\begin{array}{l}\text { Garrafad } \\
\text { a }\end{array}$ & Cascas & Coletada & $\begin{array}{c}\text { Menstruada } \\
\text { garotas }\end{array}$ & 2x ao dia \\
\hline Quando é & Próstata & $\begin{array}{l}\text { Garrafad } \\
\text { a }\end{array}$ & Caule & Cultivada & $\begin{array}{r}\text { Não } \\
\text { informado }\end{array}$ & 3x ao dia \\
\hline
\end{tabular}

Os raizeiros citaram contra indicações ao uso de alguns fitoterápicos. Segundo estes, somente aos chás ou garrafadas com sabor amargo, são estritamente proibidos o consumo pelas gestantes, por terem potencial abortivo. CASSINO (2010) relata que o sabor amargo das plantas medicinais é determinante para discernir as contra indicadas para gestantes.

Também foi observado que os raizeiros procuram adotar outras precauções no uso de plantas medicinais em forma de chás ou "garrafadas', como: posologia, toxidade e faixa etária permitida para o consumo (Quadro 2). Vale ressaltar que esses fatores ainda precisam de estudos científicos que garantam a eficácia desses componentes no tratamento de doenças.

\section{CONCLUSÃO}

O uso das espécies madeireiras e medicinais, ainda é frequente pela população da cidade de Aldeias Altas (MA). Estas representam uma alternativa econômica e medicinal para muitas pessoas na cidade. Porém, faz-se necessário mais estudos que viabilizem o uso desses recursos da natureza, para que sejam utilizadas de maneira mais sustentáveis.

\section{REFERÊNCIAS}

ARAÚJO, I. F. M.; SOUZA, L. F.; GUARÇONI, E. A. E.; FIRMO, W. C. A. O comércio de plantas com propriedades medicinais na cidade de Bacabal, Maranhão, Brasil. Natureza on line, v. 13, n.3, p. 111-116, 2015. Disponível em: <http://www.naturezaonline.com.br/natureza/conteudo/pdf/AraujolFMetal_111116.pdf>.

ALMEIDA NETO J. R; BARROS, R. F.M.; SILVA, P. R. R. Uso de plantas medicinais em comunidades rurais da Serra do Passa-Tempo, estado do Piauí, Nordeste do Brasil. Revista Brasileira de Biociência, Porto Alegre, v. 13, n. 3, p. 165-175,2015. Disponivel em: http://www.ufrgs.br/seerbio/ojs/index.php/rbb/article/view/3280

APG. An update of the Angiosperm Phylogeny Group classification for the orders and families of flowering plants: APG III. Botanical Journal of the Linnean Society, v. ENCICLOPÉDIA BIOSFERA, Centro Científico Conhecer - Goiânia, v.13 n.24; p.1169 2016 
16,p.105-121, 2009. Disponível em:< http://onlinelibrary.wiley.com/>. doi/10.1111/j.1095-8339.2009.00996.x/pdf >.

ARAÚJO, H. J. B. Agrupamento de espécies madeireiras ocorrentes em pequenas áreas sob manejo florestal do projeto de colonização Pedro Peixoto (AC) por similaridade das propriedades físicas e mecânicas. 168p, 2002. Dissertação (Mestrado em Recursos Florestais) - Escola Superior de Agricultura Luiz de Queiroz, Piracicaba. Disponível em: < http://www.teses.usp.br/teses/disponiveis/11/11150/tde-03122002-081639/ptbr.php>.

ARAÚJO, H. J. B.; SILVA, I. G. Lista de espécies florestais do Acre. Ocorrência com base em inventário florestal. Rio Branco: Embrapa-CPA/AC, 77p, 2000. Disponívelem:<https://www.agencia.cnptia.embrapa.br/Repositorio/doc48_000gebsy hpf02wx5ok0ylax2l337wy2d.pdf>.

BATTISTI, C.; GARLET, T. M. B.; ESSI, L.; HORBACH, R. K.; ANDRADE, A.; BADKE, M. R. Plantas medicinais utilizadas no município de Palmeira das Missões, RS, Brasil. Revista Brasileira de Biociências, v. 11, n. 3, p. 338-348, 2013. Disponível em: <http://www.ufrgs.br/seerbio/ojs/index.php/rbb/article/view/2457>.

BALDIN, N.; MUNHOZ, E. M. B. Educação ambiental comunitária: uma experiência com a técnica de pesquisa snowball (bola de neve). Revista Eletrônica do Mestrado em Educação Ambiental, v. 27, 2011. Disponível em: < https://www.seer.furg.br/remea/article/view/3193/1855 >.

BALDINI, K. B. L.; SILVA, J. G. Madeiras do parque nacional do Itatiaia: etnobotânica e conservação dos recursos naturais. Floresta e Ambiente, v.14, n. 2, p. 35-48, 2007. Disponível em: < http://www.floram.org/files/v14n2/v14n2a4.pdf>.

CALVI G. P; FERRAZ I. D. K. Levantamento das espécies florestais de interesse econômico e o cenário da produção de sementes e mudas na Amazônia Ocidental. Informativo Abrates, vol.24, n.2, 2014. Disponível em: < http://www.abrates.org.br/images/Informativo/v24_n2/023_2014_Isolde_Ferraz.pdf.

CERQUEIRA, P. H. A.; VIEIRA, G. C.; BARBERENA, I. M.; MELO, L. C.; FREITAS, L. C. Análise dos resíduos madeireiros gerados pelas serrarias do município de Eunápolis-BA. Revista Floresta e Ambiente, v.19, n.4, p. 506-510, 2012. Disponível em:< http://www.floram.org/articles/view/id/50489aad5ce02a6f7b00000a >. doi: http://dx.doi.org/10.4322/floram.2012.051

CASSINO, M. F. Estudo etnobotânico de plantas medicinais em comunidades de várzea do rio Solimões, Amazonas e aspectos farmacognósticos de Justicia pectoralis Jacq. forma mutuquinha (Acanthaceae). Dissertação (Mestrado em Botânica) Instituto Nacional de Pesquisas da Amazônia,135p, 2010. Disponível em: <http://livros01.livrosgratis.com.br/cp148789.pdf>.

CASTELLUCCI, S.; LIMA, M.I.S.; NORDI, N; MARQUES, J.G.W. Plantas medicinais relatadas pela comunidade residente na Estação Ecológica de Jataí, município de Luís Antonio - SP; uma abordagem etnobotânica. Revista Brasileira de Plantas 
Medicinais, v.3, n.1, p.51-60, 2000. Disponível em: <http://www.sbpmed.org.br/download/issn_00_2/artigo_5_v3_n1.pdf>.

FARIAS, L. F.; BORGES, F. V.; PEREIRA, M. P. levantamento etnofarmacológico de plantas medicinais utilizadas no Bairro Jardim Primavera, Alta Floresta - MT. Enciclopédia Biosfera- Goiânia, v.11 n.21; p. 3232, 2015. Disponível em:< http://www.conhecer.org.br/enciclop/2015b/multidisciplinar/levantamento\%20etnofar macologico.pdf>.

DANTAS, V.S.; DANTAS, I. C.; CHAVES, T. P.; FELISMINO, D.C.; SILVA, H.; DANTAS, G. D. S. Ánalise das garrafadas indicadas pelos raizeiros na cidade de Campina Grande-PB. Revista de Biologia e Farmácia, v.3, n.1, p.7-13, 2008. Disponívelem:<http://sites.uepb.edu.br/biofar/download/v3n12008/analisedasgarrafa dasindicadas.pdf $>$.

FRANCO, E.A.P.A.; BARROS, R.F.M. 2006. Uso e diversidade de plantas medicinais no Quilombo Olho D'água dos Pires, Esperantina, Piauí. Revista Brasileira de Plantas Medicinais, v.8, n.3, p.78-88, 2006. Disponível em:< http://www.sbpmed.org.br/download/issn_06_2/artigo12_v8_n3.pdf >.

FREITAS, A. V. L.; COELHO, M. F. B.; MAIA S. S. S.; AZEVEDO, R. A. B. Plantas medicinais: um estudo etnobotânico nos quintais do Sítio Cruz, São Miguel, Rio Grande do Norte, Brasil. Revista Brasileira de Biociências, Porto Alegre, v. 10, n. 1 , p.48-59,2012.

Disponível em:<http://www.ufrgs.br/seerbio/ojs/index.php/rbb/article/view/1833>.

GOMES J.I; SAMPAIO S.S. Aproveitamento de resíduos de Madeira em Três Empresas Madeireiras do Estado do Pará. Belém: Embrapa,. Comunicado técnico,n.102,2004.Disponivelem:<https://www.infoteca.cnptia.embrapa.br/bitstream/ doc/395422/1/com.tec.102.pdf $>$.

IBGE. Instituto Brasileiro de Geografia e Estatística. Disponível: http://www.cidades.ibge.gov.br/xtras/perfil.php?lang=\&codmun=210030\&search=mar anhao|aldeias-altas . Acesso: 06.Set. 2015.

LIMA, J. S.; OLIVEIRA, D. M.; JÚNIOR, J. E. N.; SILVA-MANN, R.; GOMES, L. G. Saberes e uso da flora madeireira por especialistas populares do agreste de Sergipe. Sitientibus, v. 11, v. 2, p. 239-253, 2011. Disponível em: < pkp.uefs.br/ojs/index.php/sitientibusBiologia/article/download/73/45

LEITE, M.J.H.; SILVA, L.H.; GOMES, A.D.V. Levantamento das plantas medicinais utilizadas pela população de São José dos Cordeiros, Paraíba, Brasil. Revista Verde de Agroecologia e Desenvolvimento Sustentável, v.8, n.5, p.25-29, 2013. Disponívelem:<http://www.gvaa.com.br/revista/index.php/RVADS/article/view/2496/2 $155>$.

LISTA DA FLORA DO BRASIL. 2016 Jardim Botânico do Rio de Janeiro. Disponível em: < http://floradobrasil.jbrj.gov.br/ >. >. Acesso em: 30 Març. 2016

MARANHÃO. Secretaria de Estado do Meio Ambiente e Recursos Naturais. Plano de ação para prevenção e controle do desmatamento e das queimadas no ENCICLOPÉDIA BIOSFERA, Centro Científico Conhecer - Goiânia, v.13 n.24; p.1171 2016 
estado do maranhão. Decreto $\mathrm{n}^{\circ}$ 27. 317, de 14 de abril de 2011. São Luís, Maranhão, novembro de $2011 . \quad$ Disponível em:< www.fundoamazonia.gov.br/...pt/.../Publicacoes/Plano_Estadual_do_Maranhxo.pdf

$>$.

MARTINS, A. G.; ROSÁRIO, D. L. BARROS, M. N.; JARDIM, M. A. G. Levantamento etnobotânico de plantas medicinais, alimentares e tóxicas da ilha do Combu, município de Belém, Estado do Pará, Brasil. Revista Brasileira de Farmácia, Rio de Janeiro, v. 86, n.1, p. 21-30, $2005 . \quad$ Disponível em:<http://www.rbfarma.org.br/files/pag_21a30_RBF86_1_2005_LEVANTAMENTO. pdf $>$.

NASCIMENTO, J. M.; CONCEIÇÃO, G. M. Plantas medicinais e indicações terapêuticas da comunidade quilombola Olho D água do Raposo, Caxias, Maranhão, Brasil. Revista de Biologia e Farmácia, v. 6, n. 2, p.138-151, 2011. Disponívelem:<http://sites.uepb.edu.br/biofar/download/v6n22011/plantas_medicinai s_e_indicacoes_terapeuticas_da_comunidade_quilombola_olho_dagua_do_raposo. pdf $>$.

OLIVEIRA, M.S; SILVA, E.O; GUARÇONI, E.A.E; JUNIOR, E. G. S. Espécies vegetais de uso popular no município de Coelho Neto, Maranhão, Brasil. Enciclopédia Biosfera - Goiânia, v.13 n.23; p. 1412. 2016. Disponível em:< http://www.conhecer.org.br/enciclop/2016a/ciencias\%20biologicas/especies\%20vege tais.pdf >. doi: Enciclopedia_Biosfera_2016_125.

OLIVEIRA JÚNIOR, S. R.; CONCEIÇÃO, G. M. Espécies vegetais nativas do cerrado utilizas como medicinais pela comunidade Brejinho, Caxias, Maranhão, Brasil. Cadernos de Geociências, v. 7, n. 2, p.140-148, 2010. Disponível em:< http://www.portalseer.ufba.br/index.php/cadgeoc/article/view/4523/3553 >.

RIBEIRO, D.A. I, MACÊDO, D.G. I, OLIVEIRA, L.G.S. I; SARAIVAM.E. I; OLIVEIRA, S.F.I, SOUZA, M.M.A.I \& MENEZES, I.R.A. 2014. Potencial terapêutico e uso de plantas medicinais em uma área de Caatinga no estado do Ceará, nordeste do Brasil. Revista Brasileira de Plantas Medicinais. v.16, n.4, p.912930,2014.Disponívelem:<http://www.scielo.br/pdf/rbpm/v16n4/a18v16n4.pdf>.doi:http ://dx.doi.org/10.1590/1983-084X/13_059

SANTOS, L.; SILVA, H. C. H. Levantamento de plantas medicinais utilizadas em garrafadas no assentamento rendeira em Girau do Ponciano - Alagoas: implicações para conservação de espécies lenhosas. Revista Ouricuri, Paulo Afonso, Bahia, v.5, n.2, p.081-104, $2015 . \quad$ Disponível em:http://www.revistas.uneb.br/index.php/ouricuri/article/view/1486/976 >.

SILVA, M.D.P.; MARINI, F.S.; MELO, R.S. Levantamento de plantas medicinais cultivadas no município de Solânea, agreste paraibano: reconhecimento e valorização do saber tradicional. Revista Brasileira de Plantas Medicinais, v.17, n.4, supl. II, p.881-890, $2015 . \quad$ Disponível em:< http://www.scielo.br/pdf/rbpm/v17n4s2/1516-0572-rbpm-17-4-s2-0881.pdf >. doi: http://dx.doi.org/10.1590/1983-084X/14_112 
SILVA, R. M.; FARIA, M. T. Caracterização etnobotânica e histoquímica de plantas medicinais utilizadas pelos moradores do Bairro Carrilho, Goianésia (GO). Enciclopédia Biosfera - Goiânia, v.10, n.19, p. 2808, 2014. Disponível em: < http://www.conhecer.org.br/enciclop/2014b/MULTIDISCIPLINAR/Caracterizacao\%20 etnobotanica.pdf $>$.

SILVA, W. A.; FAGUNDES, N. C. A.; COUTINHO, C. A.; SOARES, A. C. M.;CAMPOS, P. V.; FIGUEIREDO, L. S. Levantamento etnobotânico de plantas medicinais na cidade de São João da Ponte - MG. Revista de Biologia e Farmácia, v. $7, \quad$ n. 1 , p. 122-131, 2012. Disponível em: < http://sites.uepb.edu.br/biofar/download/v7n12012/levantamento_etnobotanico_de_pl antas_medicinais_na_cidade_de_sao_joao_da_ponte.pdf $>$.

SILVA, E. O.; SILVA, G. A. F. S.; CONCEIÇÃO, G. M., FONTES, E. S. Levantamento das espécies madeireiras exploradas no município de Caxias - MA. Revista Acta Tecnológica, v. 3, n. 2, p. 32-38, 2009.

SOARES, M. A. A.; BRAGA, J. R. P.; MOURÃO, A. É. B.; PARENTE, K. M. S.; PARENTE-FILHO, E. G. Levantamento etnobotânico das plantas medicinais utilizadas pela população do município de Gurinhém - Paraíba. Revista Homem, Espaço e Tempo, v. 2, p. 36-47, 2009. Disponível em:< http://www.periodicos.unir.br/index.php/propesq/article/viewFile/422/474 >.

SOBRAL, L.; VERISSIMO, A.; LIMA, E.; AZEVEDO, T.; SMERALDI, R. Acertando o alvo 2: consumo de madeira amazônica e certificação florestal no Estado de São Paulo. Belém: Imazon, 72p, 2002. Disponível em:< http://www.terrabrasilis.org.br/ecotecadigital/images/25abr\%20acertando.pdf >.

SILVA, A.J.R. \& ANDRADE, L.H.C. Etnobotânica nordestina: estudo comparativo da relação entre comunidades e vegetação na Zona do Litoral - Mata do Estado de Pernambuco, Brasil. Acta Botanica Brasilica, v. 19, n 1, p. 45-60, 2005.Disponível em:< http://www.scielo.br/pdf/abb/v19n1/v19n1a05.pdf >.doi: http://dx.doi.org/10.1590/S0102-33062005000100006

VIEIRA, L.S.; SOUSA, R.S.; LEMOS, J.R. Plantas medicinais conhecidas por especialistas locais de uma comunidade rural maranhense. Revista brasileira de plantas medicinais, v.17, n.4, supl. III, p.1061-1068, 2015. Disponível em:< http://www.scielo.br/pdf/rbpm/v17n4s3/1516-0572-rbpm-17-4-s3-1061.pdf>. doi: http://dx.doi.org/10.1590/1983-084X/15_009 